\title{
History of EISCAT - Part 2: The early history of EISCAT in Finland
}

\begin{abstract}
J. Oksman
Professor emeritus of the University of Oulu, Finland

Received: 24 August 2011 - Revised: 15 October 2011 - Accepted: 18 October 2011 - Published: 19 December 2011

Abstract. The idea of a Nordic incoherent scatter facility, proposed by Bengt Hultqvist, was for the first time discussed among representatives of the three Nordic countries Norway, Sweden and Finland in 1969 in Oulu, Finland. In the years to follow, when other countries joined in and the plans of the facility to be built gradually received concrete forms, Finland participated in the planning work, in spite of the large costs to be expected. When in negotiations with the Nordic partners in 1975 the share of Finland in EISCAT was reduced to five per cent and when the existing facilities and personnel at Sodankylä could be taken into account in the Finnish share, the Academy of Finland was finally ready to join EISCAT.
\end{abstract}

\section{The first step is taken at Oulu}

My colleague Prof. Martti Tiuri of Helsinki University of Technology sent me in September 1969 a copy of the protocol from Lindau, West Germany, where a meeting of European ionospheric physicists had been held. Two competing possibilities to extend the incoherent scatter (I.S.) measurements to high latitudes in Europe had been proposed there: a tristatic Scandinavian facility, suggested by B. Hultqvist from Sweden, and a shipborne radar, proposed by F. du Castel from France. The latter proposal was preferred by the meeting.

Tiuri called me soon afterwards. He told me that he and Hultqvist, whom he had met at Lindau, had decided to ask me to organize a meeting in Oulu. The aim was to discuss possibilities to start incoherent scatter (I.S.) measurements in Nordic cooperation. Tiuri gave me a list of seven scientists from Finland, Norway and Sweden who should be invited to the meeting. I agreed, and on 29 November 1969 we met in the premises of the Department of Electrical Engineering of the University of Oulu.

Hultqvist who had been behind one of the proposals made at Lindau, as well as a similar proposal made in the General Assembly of URSI in Ottawa in August 1969, had prepared a daft P.M. for our meeting. After a discussion of several hours we agreed on a final P.M.

Our P.M. contained a short outline of the I.S. method, a list of existing I.S. stations and reasons for extending the network of stations to auroral latitudes. Because the measurement facility would be too expensive for a single country, we suggested that the plan should be realized as a cooperative Nordic programme. Placing the stations of the system in three countries, several hundred kilometres apart, would also yield a favourable measurement geometry.

Our plan was based on a previous study, made by D. R. Moorcroft, on the structure of a similar measurement system proposed for Northern Canada. Our system would consist of three stations, one in each of the three Nordic countries, natural locations being Kiruna in Sweden, Troms $\varnothing$ in Norway and Sodankylä in Finland. We also gave preliminary technical parameters of the facility and estimated, based on the estimate made for the Canadian system, the building costs to be five and the annual running costs half a million Canadian dollars. We thought, optimistically, that the system could be ready by 1975 , just before the beginning of the International Magnetospheric Study (IMS) in 1976. We suggested that a Nordic committee be established to study the details of the plan. 


\section{Other countries join in}

It soon turned out that our cost estimates were far too low. Thus the system could not be realized by the Nordic countries alone. Fortunately, other countries soon joined us.

In his letter on 29 May 1970 to a number of ionosphere physicists, including Hultqvist, du Castel suggested for financial, scientific and technical reasons that the two facilities suggested at Lindau should be combined by erecting a relatively small radar in the auroral zone for IMS and moving it afterwards further South. This suggestion was, however, criticized in their letter on 9 June to Hultqvist by Taylor and Watkins from England; they preferred a large permanent radar in the auroral zone.

Obviously to clarify the situation, Hultqvist organized in September 1970 in Stockholm a meeting and invited on 31 August by a telex scientists from the Nordic countries as well as from France, Germany and United Kingdom to attend it. The meeting was, according to the suggested agenda, to review the status of the two proposals and study possibilities of combining them to a single European project. I do not have the minutes of the Stockholm meeting but basing on the minutes of the meeting in Nançay a month later it seems that it was decided to concentrate the European efforts to an I.S. facility in the auroral zone. Hultqvist had reached his goal!

In Nançay a long step forward was taken towards the realization of the I.S. facility. It was agreed that a high-frequency (or UHF) multistatic facility, working at a frequency in the range $800-1300 \mathrm{MHz}$ and a low-frequency (or VHF) monostatic radar with a frequency between about 50 and $200 \mathrm{MHz}$ should be studied. The groups in different countries were to study the different parts and aspects of the facility. For instance, the antenna for the VHF radar was Finnish responsibility.

I attended the Second European Regional Meeting of URSI at Reading, England, on 30 March to 2 April 1971, where, in addition to other matters, also the realization of the combined European I.S. project and its scientific objectives were discussed.

The fourth meeting of the preparatory committee was held in May 1971 at Otaniemi near Helsinki, with Tiuri as chairman. Nobody from UK was present this time but other countries were represented, including eight persons from the host country. The work in the meeting was based on the assumption that both the high-frequency and the low-frequency facility could be built, although du Castel voiced some doubts as to the possibility of getting money for such an extensive system.

The progress reports, presented in the Helsinki meeting, contained the results of studies on the structure of the different parts of the facility. It was decided to publish a report with the results of a feasibility study, to be prepared. The report would consist of 50 to 100 pages and have the title "A European Incoherent Facility in the Auroral Zone". Hultqvist gave the system the later established name "Eu- ropean Incoherent Scatter Facility (EISCAT)". The report, containing 11 reference reports, was finalized next month at Titisee; because its green covers it received later the name "Green Book".

In the following months it was attempted to push the EISCAT venture forwards in all countries involved, including Finland. The Space Science Section of the Science Research Council of the Academy of Finland, chaired by Tiuri, gave, of course, a strong support to EISCAT in the document (in Finnish) "Programme for developing the study of near space in Finland in the years 1972-76". The Section also set up a working group to promote the EISCAT venture and called me as its chairman. The reason for nominating me was that Tiuri wanted to concentrate his efforts on promoting his idea of a microwave research station (called "Big Pumpkin" due to the shape of the radome of its antenna) at Kirkkonummi near Helsinki and leave EISCAT in my hands.

\section{How to proceed?}

The EISCAT venture had so far been discussed among us scientists only, and we did not have the mandate to make decisions on financing the facility. It was difficult to see how we should proceed. Du Castel decided now to ask the Council of Europe for help. On his initiative its Committee on Science and Technology founded the Study Group on Auroral Ionosphere, which invited a group of scientists to attend its first meeting at the end of February 1972 in Paris. The authors of the Green Book, including Tiuri, were invited, and, in addition, Henry Rishbeth from UK and I.

When the Finnish Foreign Office learned that it was planned to promote the EISCAT venture with the help of the Council of Europe and that Tiuri and I would participate in the meeting in Paris, it asked the Finnish Embassy in Paris for help. The embassy invited Tiuri and me to lunch to a fine fish restaurant, and during the meal we were delicately told that because Finland had in the Council an observer status only, the Council would not be able to take care of administration of EISCAT if Finland participated in the venture. We were asked to keep this fact in mind.

We conveyed this negative message to the meeting, held on the following day in the Paris office of the Council of Europe. On the positive side we learned in the meeting that detailed studies on the parts of the facility had been started in several countries: the Frenchmen were planning the UHF transmitter, the British the VHF transmitter and the Germans the UHF antennas. In order to avoid transfer of funds across the borders, it was decided (at this stage) that each country would finance those parts of the equipment which it had planned. Funds would be sought for in different countries at the Science Research Council level, and the administrative side of the venture was (optimistically) expected to become clear before the end of the year. 


\section{A decisive step forward is taken}

Mr. A. Sandbo, chairman of Norwegian Science Research Council, wrote in the beginning of July 1973 to the representatives of different countries a letter where he stated that time was ripe to organize a meeting between the institutes in various countries interested in EISCAT. He proposed that the President of URSI, Prof. W. J. G. Beynon, organize such a meeting.

Beynon accepted the proposal and called a meeting to London for 25 October 1973. He hoped that every country interested in EISCAT would send to London at least one senior scientist and one senior science administrator.

Because no official decision on EISCAT had been made in Finland, I decided to attend the meeting in London on my own initiative. I also tried - but in vain - to get the Ministry of Education to send a science administrator to London. I was, therefore, the only Finn in London; from most other countries at least one scientist and one administrator were present.

In the meeting, the scientific part of the project and the plans for technical solutions of the EISCAT facility were reviewed. We decided to found a Steering Committee to develop the EISCAT project further and hoped that each country would nominate one scientist and one science administrator to it. The Committee was given the task to (1) prepare an updated feasibility study for EISCAT, detailing the interphases, with refined estimates of costs, (2) to recommend possible methods of managing the project and operating the facility and (3) to make suggestions on how to divide the costs between the participating countries.

After the London meeting I sent a letter to the Academy of Finland, proposing that the Academy nominate the Finnish representatives to the Committee founded in London.

The Finnish Ministry of Education had in the meantime asked the Academy of Finland to deliver a statement on possible participation of Finland in the EISCAT project. The Science Research Council of the Academy considered in its statement (strongly influenced by Tiuri) that the EISCAT project was scientifically very significant and that Finland's participation in it was important. Because the project was estimated to be relatively expensive, its funding should, in the opinion of the Council, be arranged in the state budget with a specific appropriation provided to this purpose. Finally the Council stated that Finland ought to be firmly involved in the planning of the EISCAT project and that she should necessarily send her representative to EISCAT Steering Committee; I would be a suitable person. In the opinion of the Council, it would be important to rapidly start to work out the organization and funding of the project.

The Steering Committee, founded in London, met, on the invitation of the President of Max-Planck-Gesellschaft (MPG), Dr. F. Schneider, the first time at the Headquarters of MPG in Munich in 2 February 1974. Because no Finnish delegates to the Steering Committee had been nominated yet, I went to Munich on my own initiative.

In March 1974 the Finnish Ministry of Education nominated the deputy chief of office Osmo Ranta of the Ministry and me to members of the Steering Committee of EISCAT. Finland was finally officially involved in EISCAT!

\section{Encountered problems and their solutions}

Several meetings of the Steering Committee followed in 1974 and 1975. We had lengthy discussions on the text of the agreement and on the different parts of the facility. In these discussions many problems of most varied kinds were encountered.

It had been assumed in the beginning that France would design and build the UHF transmitter and UK the VHF transmitter. We soon realized, however, that it would be impractical and costly to build separate transmitters for UHF and VHF. A great deal of money would be saved by combining them to a single unit.

The situation became, however, more complicated. It turned out that the participation of UK in EISCAT was uncertain. Thus we decided to go ahead with UHF only and add the VHF system later if UK decided to join. This meant that the advantage of combining the two transmitters would be lost, causing added costs.

The Frenchmen soon found out that funding the UHF transmitter would be too expensive for France alone. They wanted, therefore, to divide the costs between the participating countries more evenly. Pooling of funds was thus necessary. As a first step, France and Germany decided to form a common pool.

The transmitter was to be equipped with klystrons from the American company Varian. They were directly available for another frequency but it was expected that Varian would be able to modify them for EISCAT. This assumption turned out to be far too optimistic: Varian had major problems in building the klystrons, resulting in a delay of several years in the start of EISCAT measurements.

A big problem was how to divide the available funds between different parts of hardware, especially transmitters and antennas. Larger (and thus more costly) antennas would mean less money left for transmitters, and vice versa. Lengthy discussions on the kind, number and size of antennas were held. They were, until the end of 1975, complicated by the fact that Tiuri was interested in the chain antenna which, in his opinion, was suitable for the VHF part of EISCAT. He planned that the antenna could be constructed in Finland and would be a part of the Finnish in kind contribution to EISCAT. Later the chain antenna was dropped from discussions because of its poor steerability and problems with snow, and a completely different type of antenna was chosen. 
The buildings and instrumentation, excluding the transmitters and antennas, at the three sites Kiruna, Troms $\varnothing$ and Sodankylä were agreed to be the responsibility of the Nordic countries. The receivers would be built by Sweden and Finland, and Norway promised to deliver the computers for all sites.

Concerning the sites, it was noticed that some complications might be caused by the fact that The Geophysical Observatory at Sodankylä belonged to the Finnish Academy of Science and Letters (a private organization) and not to the Academy of Finland (a governmental organization) which was to sign the agreement.

Because the Academy of Finland was used to support scientific projects lasting a few years only, it had difficulties in making a commitment to support the EISCAT project for an extensive period of time. Finally, it had to accept the new situation and review its funding principles. (Long-time funding became later a standard practice in satellite programmes.)

The administration of EISCAT caused us a lot of concern. Because of the relatively small size of the project, no intergovernmental organization like European Space Agency was considered feasible, and some common organ of national science councils could be envisaged instead. The solution was a foundation according to the Swedish law with headquarters at Kiruna.

In addition to science, technology and economics, even politics played, at times, a role: in 1974 the decision of France on joining EISCAT had to be delayed to fall due to the presidential elections! A second worry about France was the news, also in 1974, that the future of CNET (Centre National d'Etudes des Télécommunications), which was heavily involved in EISCAT, was at stake because of reorganization of French research institutes. Fortunately, this worry turned out to be unfounded.

Also foreign policy popped in: it was thought that it would be easier to accept EISCAT at governmental level if USSR joined in. In fact, Soviet scientists had expressed their interest in EISCAT, and the Soviet Academy of Science had taken a positive stand on the project. It had been learned that Soviet Union was planning to build an I.S. station at Verhnetulomsk near Apatity in Cola Peninsula. We Finns were, due to our location, especially suited to contacts with Soviet Union, and I informed Prof. B. E. Brunelli of Polar Geophysical Institute in Apatity with a letter on EISCAT.

Although cooperation with Soviet Union would possibly have been scientifically useful and politically purposeful, it was finally decided not to invite Soviet Union to join EISCAT before the agreement was signed. No formal cooperation exists even to-day.

\section{The project group}

The Steering Committee was too large and varied in membership to be able to effectively take care of planning and con-

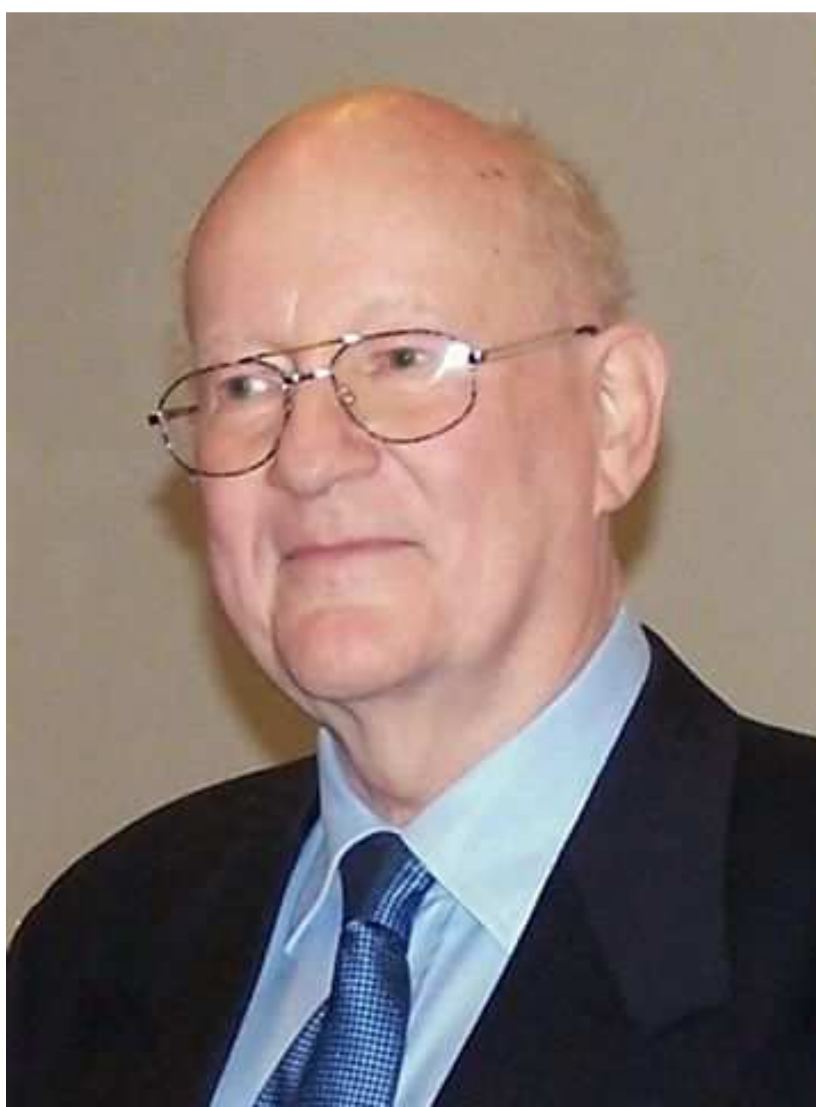

Figure 1. Tor Hagfors, Director of EISCAT in 1975-1982 (Photo by Andreas Blome, MPI für Sonnensystemforschung, on the occasion of Hagfors's 75th birthday on 3 February 2006).

struction of the EISCAT facility. Therefore the Committee decided in its meeting in July 1974 in Hamburg to establish a Project Group, with Tor Hagfors as its chairman, for the period preceding the establishment of EISCAT association. Each country was asked to nominate a member to this group, and Ranta and I decided to select Tauno Turunen from Sodankylä to be the Finnish member. The Project Group met, once a month, seven times before it was abolished in 1975 .

The group met great problems in formulating the bids. To start with, it tried adhere to the principle that the invitations for bids for a particular major component should be written in accordance with the existing legal rules in the country responsible for funding that component. Because France and Germany had agreed to pool funds for the purchase of the UHF transmitter and antennas, the invitations for bids for these items would have to be written to comply with the regulations in both countries.

The situation was, in fact, more complicated. It was possible that UK decided, after all, to join EISCAT, and in this case also a VHF transmitter would have to be built. But as clear savings would be obtained by integrating the UHF and VHF transmitters, this transmitter should necessarily be 
contracted to one company. Thus UK (if it joined EISCAT) would have to join also a common pool with France and Germany.

Finally the group decided to issue international tenders to all major components of the facility. This meant pooling all the funds for transmitters and antennas.

\section{The agreement is accepted}

The EISCAT agreement was ready to be initialled in the meeting of the Steering Committee in January 1975 in Paris. (The initialling was defined to mean a limited acceptance of the text of the agreement and did not imply a financial commitment to the project.) The representatives of France, Germany and Norway were ready to initial the updated agreement and did this by the end of the meeting. The representatives of Sweden and Finland did not have the authority to do this; they had to wait for the decisions of their governments to be made in April in Sweden and in March in Finland. In UK the governmental decision was delayed even more.

The agreement was made between the scientific research councils in five countries (without UK) but it contained specific clauses on the adjustment in the number of members of the association organs and in the overall financial commitments if UK joined the association before 30 June 1975. It turned out that EISCAT had to wait even beyond this deadline.

The agreement contained changes in the administration of EISCAT. The Steering Committee and the Project Group would be dissolved and replaced by the Council and the Scientific Advisory Committee (SAC).

The provisional Council met for the first time on 17 July 1975 in London. By that time Finland had initialled the EISCAT agreement and had been able to nominate her representatives to the Council; they were Osmo Ranta of the Ministry of Education and Prof. Antti Siivola of the Academy of Finland. I had been nominated as the Finnish representative in SAC.

\section{Funding decisions}

The unclear situation concerning the number of systems (UHF only or UHF + VHF) and the number of participating countries (five or six) caused uncertainty in the total investment cost and the contributions of individual countries. Until the fall of 1975 EISCAT had to work according to the first alternative. Accordingly, the major participating countries Germany and France discussed in their meeting in Paris at the end of May 1974 the distribution of funding for the case of no VHF facility. They agreed that the sum of investments and the running costs in $11.5 \mathrm{yr}$ would be divided between France, Germany and the Nordic countries into three equal parts.
The Nordic countries agreed to reduce the contribution of Finland, as compared to those of Norway and Sweden, because the latter ones would expect a greater advantage from the project. In spite of this, the Finnish share was frightening to me. In my mind Finland would be unable to pay that much. Fortunately I found a way to save the situation.

Svante Westerlund of Kiruna Geophysical Institute (KGI) came from a meeting in Paris and informed me that the price estimate of a new building for Kiruna was 925000 SEK (Swedish crowns) and that it had been assumed in Paris that the building for Sodankylä would have the same price. This gave me the idea of "selling" the building of the ionospheric station at Sodankylä - which had, because of the end of oblique soundings to Lindau, just become almost empty to EISCAT for the price of the Kiruna building. Because an existing house would be used instead of building a new one, Finland would save a lot of money.

I prepared a tentative proposal for the distribution of costs in Scandinavia basing on this idea. To Westerlund's estimate of the cost of the Kiruna site I added the cost of the existing power line, road, measuring instruments, furniture and other similar items. When I further added the cost for building a living house, needed for EISCAT personnel, I could reduce the Finnish share to the capital cost of EISCAT by one million FIM.

As the plans for EISCAT did not include any scientific personnel for Sodankylä (contrary to the case at Kiruna and Troms $\emptyset$ ), I suggested that this were compensated for by paying the salaries of two existing Finnish scientists with overheads. When I added the salaries of existing maintenance personnel and other running costs of the station, I could considerably reduce the amount of extra annual payments at Sodankylä. The situation started to be brighter: when the Finnish contribution to the total cost during the operation time of EISCAT had been calculated to be 6.25 MFIM, the sum of existing capital and running expenditures at Sodankylä would already cover 2.63 MFIM. Because the remainder 3.62 MFIM was to be paid in about $10 \mathrm{yr}$, the participation of Finland in the project began to seem perhaps possible.

The funding question was discussed at a meeting on 19 November 1975, in Oslo between the representatives of the Nordic countries, including Osmo Ranta from Finland. In the discussions it was taken into account that UK had, at this stage, decided to join EISCAT. Because also the VHF transmitter, receiver and antenna would now be built, the overall cost of EISCAT would be increased but, because UK would pay one fourth of the costs, the share of the Nordic countries would be decreased from one third to one fourth.

When Ranta informed the meeting on the weak financial situation in Finland, the meeting decided, after a long discussion, to change the relative contributions of the Nordic countries: Finland would pay only $20 \%$ of the Scandinavian share and the other two countries $40 \%$ each. The proportions 
of the contributions would thus be 1:2:2 instead of previous 7:9:9 and the Finnish share of the total cost of EISCAT 5\%.

On Ranta's initiative the representatives of Sweden and Norway were ready to go even further: they devised a scheme where the Finnish share in investment costs could be lower than $5 \%$ if this were compensated for by an equal increase in running costs during the first six years. Because this scheme would have been complicated (and humiliating for Finland), it was, however, dropped later.

Ranta succeeded, after his return to Finland, to get from the Academy of Finland the promise to pay as its share $5 \%$ of EISCAT costs. The final Finnish share of the investment cost (in addition to the existing investments at Sodankylä), to be paid in the years 1976-1978, was, accordingly, 1958000 FIM, and the annual running costs (in addition to the existing costs) 129000 FIM. As these were still excessively big sums for the Academy, dedicated funds from the state budget would be required. It turned out that the Academy succeeded in getting them.

\section{Concluding remarks}

It was finally clear that Finland could join EISCAT. Osmo Ranta and I had succeeded in negotiating a financial scheme which both the Nordic partners and the Academy of Finland could accept. This result was of great importance to the future of ionospheric research in Finland.

The fact that the Finnish share was only $5 \%$ of the total budget of EISCAT meant that Finnish scientists had at their disposal only $5 \%$ (or annually $50 \mathrm{~h}$ ) of the total measurement time available to all member countries (estimated as $1000 \mathrm{~h}$ per year). They had, however, also access to the results of the common measurements, estimated to cover another $1000 \mathrm{~h}$ per year. In addition, they had the right to combine their measurements with those of scientists from other associates. The agreement had thus a good benefit to cost ratio for Finland.

In my opinion, it was also fortunate to the EISCAT community that Finland could become a member of the EISCAT family: inclusion of the territory of Finland provided EISCAT with a favourable measurement geometry, and it has turned out that Finland has been able to make valuable contributions to the hardware and software of EISCAT. Finnish scientists have actively participated in EISCAT's scientific and administrative work, and the Finnish site personnel has, in addition to taking good care of the equipment at Sodankylä, been able to help, at times, other sites in their problems.
Edited by: R. J. Pellinen

Reviewed by: B. Hultqvist and another anonymous referee

\section{References}

This article is based on correspondence, notes and minutes of meetings, contained in the collection of J. Oksman, stored in the archives of the University of Oulu, Finland. 